\title{
Single Point Diamond Turning of Calcium Fluoride Optics
}

\author{
Xichun Luo ${ }^{1, a}$, Jining Sun ${ }^{1, b}$, Wenlong Chang ${ }^{1, c}$ and James M Ritchie ${ }^{1, d}$ \\ ${ }^{1}$ School of Engineering and Physical Sciences, Heriot-Watt University, Edinburgh, EH14 4AS, UK \\ aX.Luo@hw.ac.uk, bJS173@hw.ac.uk, 'WC129@hw.ac.uk, dJ.M.Ritchie@hw.ac.uk
}

Keywords: diamond turning, diamond tool wear, $\mathrm{CaF}_{2}$ optics, brittle fracture

\begin{abstract}
This paper aims to develop a cost-effective diamond turning process to obtain nano-smooth $\mathrm{CaF}_{2}$ optics. Diamond tool wear was also carried out through a number of cutting trials. Three $\mathrm{CaF}_{2}$ specimens (diameter of $50 \mathrm{~mm}$ and thickness of $5 \mathrm{~mm}$, crystal orientation of (111)) were diamond turned on an ultra precision lathe (Moore Nanotech 350UPL) by a number of facing cuts. In the cutting trials feed rate varied from $1 \mu \mathrm{m} / \mathrm{rev}$ to $10 \mu \mathrm{m} / \mathrm{rev}$. White spirit mist was used as the coolant. Cutting forces were measured by a dynamometer (Kistler BA9256). Surface roughness of the $\mathrm{CaF}_{2}$ optics and tool flank wear were measured by a white light interferometer (Zygo Newview 5000) and a scanning electron microscope (FEI Quanta 3D FEG), respectively. It was found that using a feed rate of $1 \mu \mathrm{m} / \mathrm{rev}$ surface roughness Ra of $2 \mathrm{~nm}$ could be obtained. When the ratio of the normal cutting force to the tangential cutting force was lower than 1 tool wear would initiate. In diamond turning of calcium fluoride abrasive wear was the main tool wear mechanism. Using white spirit mist as thecoolant could avoid generation of thermal type brittle fracture on the machined $\mathrm{CaF}_{2}$ surfaces.
\end{abstract}

\section{Introduction}

Calcium fluoride $\left(\mathrm{CaF}_{2}\right)$ is an optical material which is highly transmissive in both ultraviolet and infrared ranges. It is particularly well suited for manufacturing lenses, prisms and mirrors for dark field imaging systems and large-scale microlithography systems and excimer lasers [1]. Single point diamond turning has been applied in the manufacturing of $\mathrm{CaF}_{2}$ optics to cut rough blanks into semi-finished optics [2, 3, 4]. Diamond turned $\mathrm{CaF}_{2}$ optics will be polished by magnetorheological finishing (MRF) or floating polishing in order to obtain the required nano-smooth surfaces and remove subsurface damage layers [5].

$\mathrm{CaF}_{2}$ is a typical brittle material. It possesses low fracture toughness and low hardness, but an extremely high thermal expansion coefficient (5.8 times that of silicon) and very low thermal conductivity ( $1 / 17$ that of silicon). For these reasons special attention needs to be paid to the thermal problem in process development. Running large numbers of diamond turning trials while using a straight-nosed diamond tool, Yan et al. [6] found that there were two types of brittle fracture on the machined surface. A-type brittle fracture which was 1 to $2 \mu \mathrm{m}$ in size appeared in a cutting region when a high feed rate was used. On the other hand B-type brittle fracture which was of the order of $100 \mu \mathrm{m}$ in size was observed in low feed rate cutting regions. Further studies have found that A-type brittle fracture is due to the size effect and crystallographic effect of the ductile-brittle transition. B-type brittle fracture results from thermal effects. Performing dry cutting could eliminate B-type brittle fracture, but the tool wear will become another problem.

This paper aims to develop a cost-effective diamond turning process to obtain nano-smooth $\mathrm{CaF}_{2}$ optics. Economical machining feed rate to maintain damage-free (both mechanical and thermal) nano-smooth diamond turned $\mathrm{CaF}_{2}$ optical surfaces will be investigated through experimental studies.

\section{Theoretical maximum feed rate to maintain ductile machining mode}

Same as for other brittle materials like $\mathrm{Si}$ and $\mathrm{Ge}$, diamond turned $\mathrm{CaF}_{2}$ surfaces are produced by a combination of brittle fracture and ductile mode removal mechanisms. Above the brittle to ductile transition point, the effective chip thickness is bigger than the so-called critical depth of cut, so 
micro-fracture damage occurs and the removal is by brittle fracture. Below the transition point, the effective chip thickness is smaller than the critical depth of cut, so plastic deformation takes place and ductile regime removal is achieved. For $\mathrm{CaF}_{2}$, its critical depth of cut $\left(\mathrm{d}_{c}\right)$ is about $0.1 \mu \mathrm{m}$. It is obtained by [7]:

$$
d_{c}=\beta \frac{E}{H}\left[\frac{K_{c}}{H}\right]^{2} .
$$

where $\beta$ is a constant. $E, H$ and $K_{c}$ are elastic modulus, hardness and fracture toughness of $\mathrm{CaF}_{2}$ respectively. The maximum feed rate for "ductile mode" diamond turning can be calculated by [7]:

$$
f_{\max }=d_{c} \sqrt{\frac{R}{2\left(d_{c}+y_{c}\right)}} .
$$

where $R$ is the tool nose radius and $y_{c}$ is the surface damage depth. Based on Eq. (2), $f_{\max }=6 \mu \mathrm{m}$ was obtained when $\mathrm{R}=2 \mathrm{~mm}$. However, this is only a theoretical estimation. More accurate value will have to be obtained through cutting trials.

\section{Cutting trials}

Setup for diamond cutting trials. The cutting trials were carried out on an ultra precision diamond turning machine - Moore Nanotech 350 UPL. This machine utilizes hydrostatic linear bearings and linear motors for linear controlled motions, and an air bearing spindle with a directly coupled servo motor drive. High resolution position and angular encoders are used throughout, which with a high speed electronic controller, ensure a high level of controlled motion performance. The experimental setup is shown in Fig. 1. The $\mathrm{CaF}_{2}$ work piece was attached to the vacuum chuck. A diamond tool was installed on a tool holder which was mounted on a kistler dynamometer. Two coolant nozzles were used in the cutting trial.

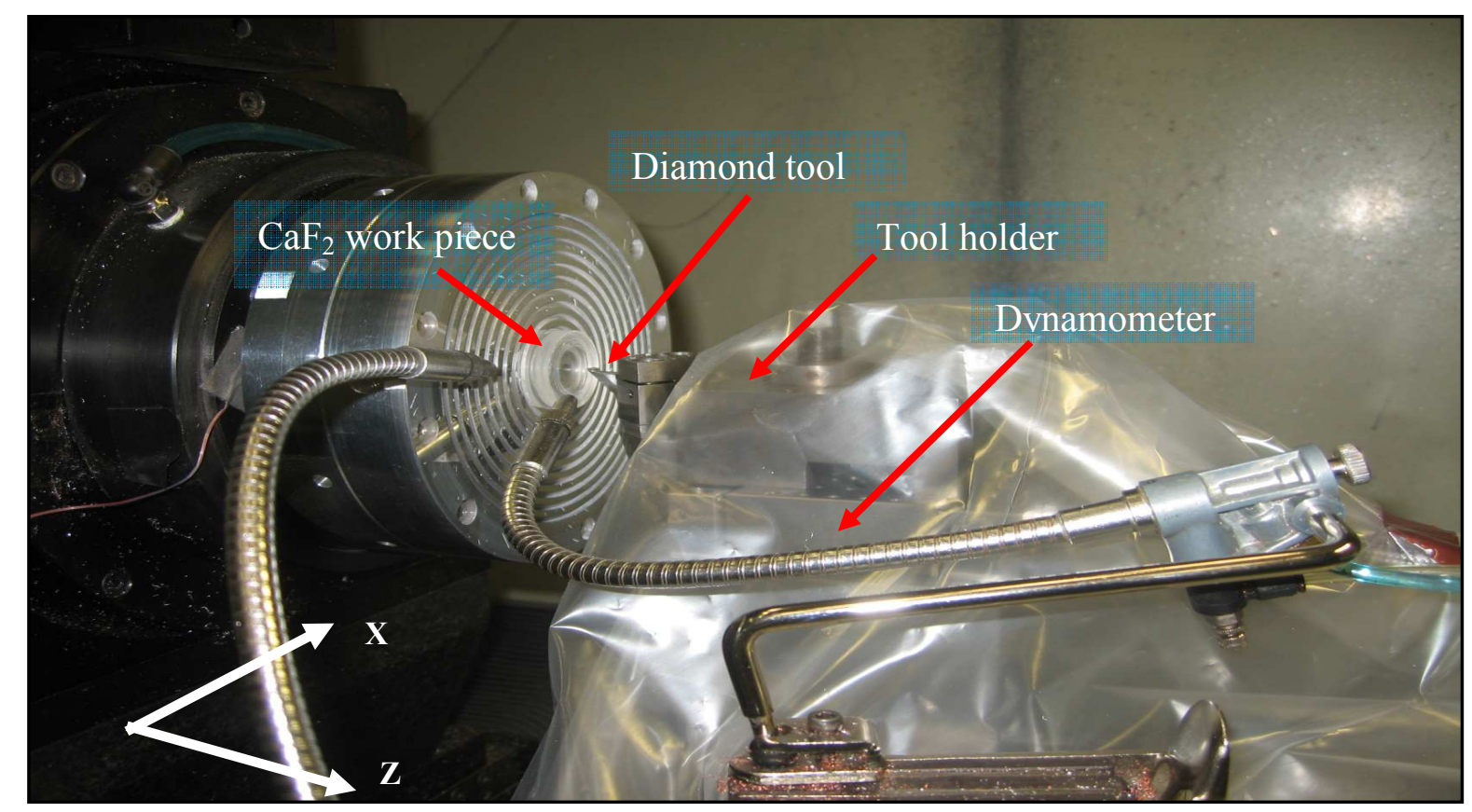

Fig. 1 Experimental setup 
Machining conditions. Two $\mathrm{CaF}_{2}$ work pieces $(50 \mathrm{~mm}$ diameter, $5 \mathrm{~mm}$ thick, (111) face) were diamond turned by using the machining conditions listed in Table 1. The diamond tool travelled from outside toward the work piece centre in the cutting process. The cutting scheme is shown in Fig. 2, in which the tool feed rate varied from $10 \mu \mathrm{m} / \mathrm{rev}$ to $1 \mu \mathrm{m} / \mathrm{rev}$ with a cutting length of $0.5 \mathrm{~mm}$.

Table 2 Machining condition and tool geometry

\begin{tabular}{l|l|l|l|l|l}
\hline Spindle speed & $1,200 \mathrm{rpm}$ & Depth of cut & $10 \mu \mathrm{m}$ & Feed rate & $1-10 \mu \mathrm{m} / \mathrm{rev}$ \\
\hline Coolant & White spirit & & & & \\
\hline Tool rake angle & $-15^{\circ}$ & Clearance angle & $10^{\circ}$ & Nose radius & $2 \mathrm{~mm}$ \\
\hline
\end{tabular}

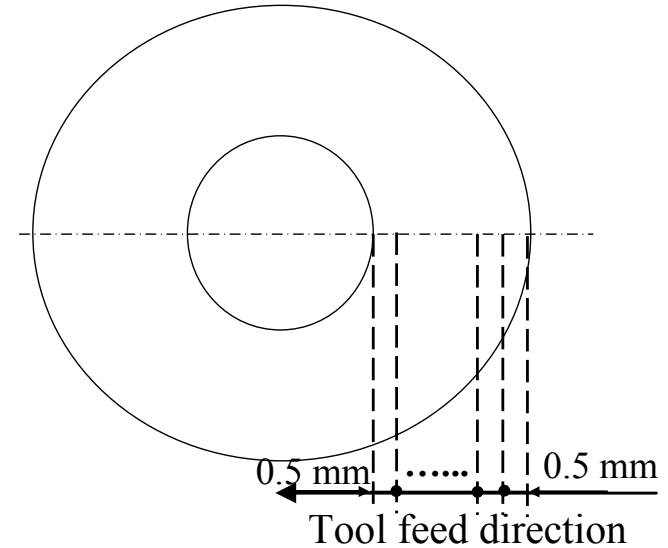

Fig. 2 Cutting scheme

Sample measurement and inspection. A Zygo Newview 5000 white light interferometer was used to measure the machined surface roughness. A Form Talysurf $120 \mathrm{~L}$ was utilized to measure the form accuracy of the machined surface. The machined work piece surface and diamond tool before and after cutting trials were also inspected by a FEI Quanta 3D Scanning Electron Microscope (SEM) and an atomic force microscope (DI Dimension 3100).

\section{Results and discussions}

Surface roughness and form accuracy. Fig. 3 shows the variation of surface roughness $(\mathrm{Ra})$ when cutting sample 1 under different feed rates. It can be seen that when a feed rate of $1 \mu \mathrm{m} / \mathrm{rev}$ was used surface roughness ( $\mathrm{Ra}$ ) of $2 \mathrm{~nm}$ was achieved. Surface roughness Ra was lower than $4 \mathrm{~nm}$ when the feed rate varied from $1 \mu \mathrm{m} / \mathrm{rev}$ to $10 \mu \mathrm{m} / \mathrm{rev}$. The measured surface topography by SEM confirmed that ductile

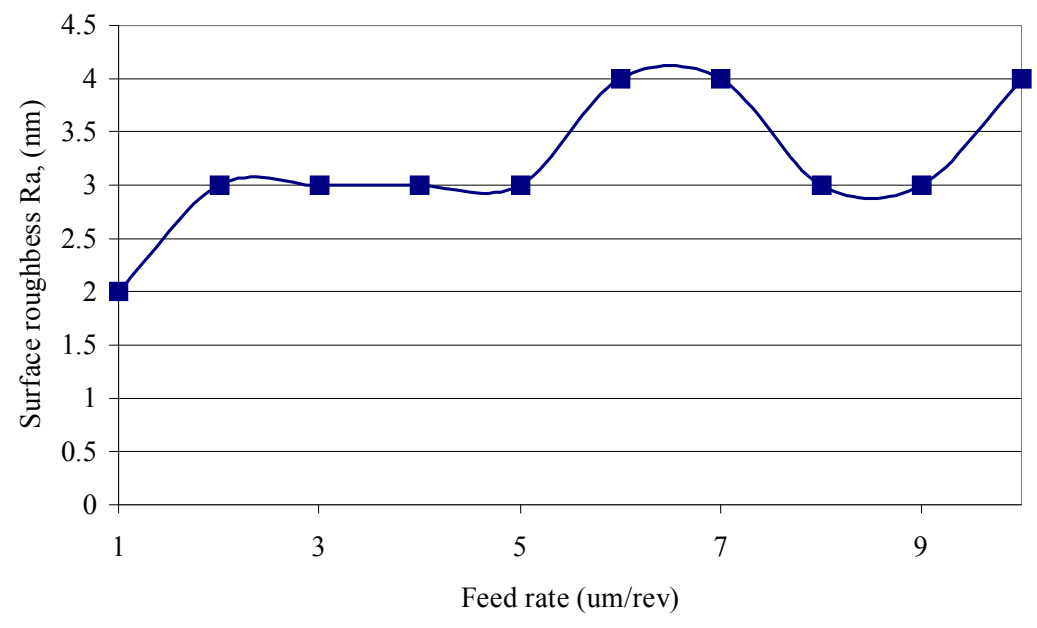

Fig. 3 Surface roughness of the machined surface against feed rate for sample 1 mode cutting was achieved in the cutting trials. However, as shown in Fig 4. the peak to value of the machined surface began to increase when the feed rate was higher than $5 \mu \mathrm{m} / \mathrm{rev}$. Therefore, a feed rate of $5 \mu \mathrm{m} / \mathrm{rev}$ is recommended to cut $\mathrm{CaF}_{2}$ in order to obtain nano-smooth surface and good form accuracy.

Fig. 5 shows the machined surface roughness of sample 2 in which a sharp rise of surface roughness was observed. When a feed rate of $10 \mu \mathrm{m} / \mathrm{rev}$ was used the surface roughness $\mathrm{Ra}$ was above $10 \mathrm{~nm}$. It indicated that brittle fracture had occurred on the machined surfaced due to tool wear. Later inspection of the machined surface and the diamond tool by SEM confirmed this conclusion. 


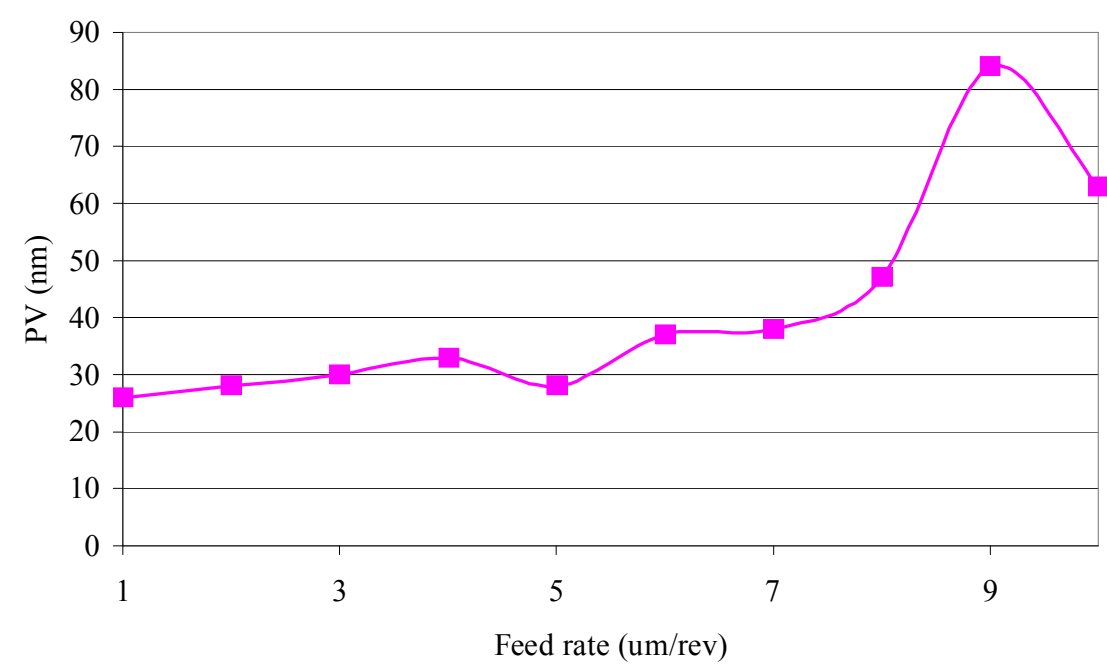

Fig. 4 Form accuracy of machined $\mathrm{CaF}_{2}$ surface under different feed rates for sample 1

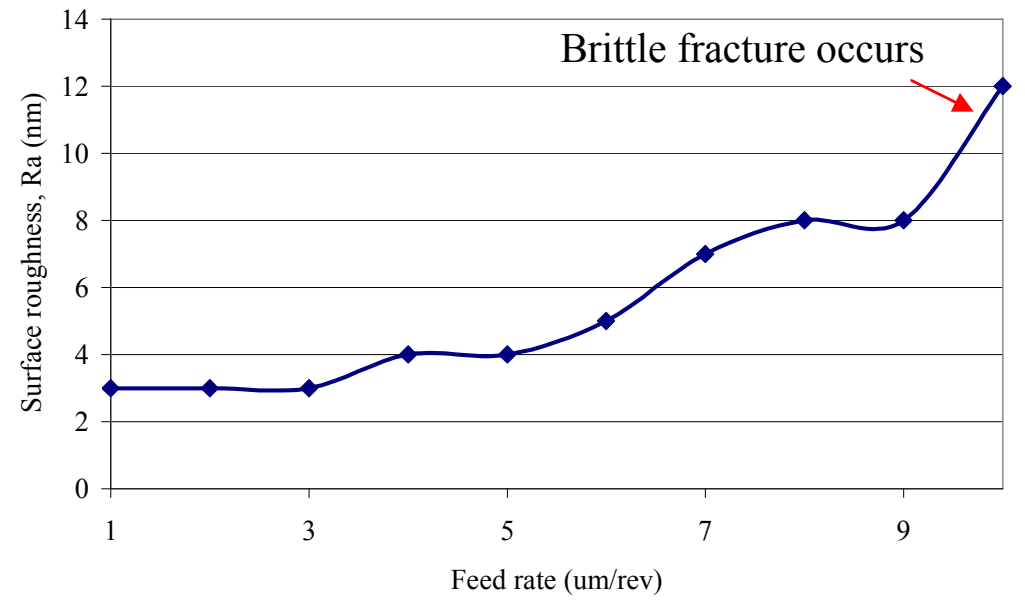

Fig. 5 Surface roughness of machined surface against feed rates for sample 2

Cutting forces. Cutting forces contain very useful information about the state of the machining

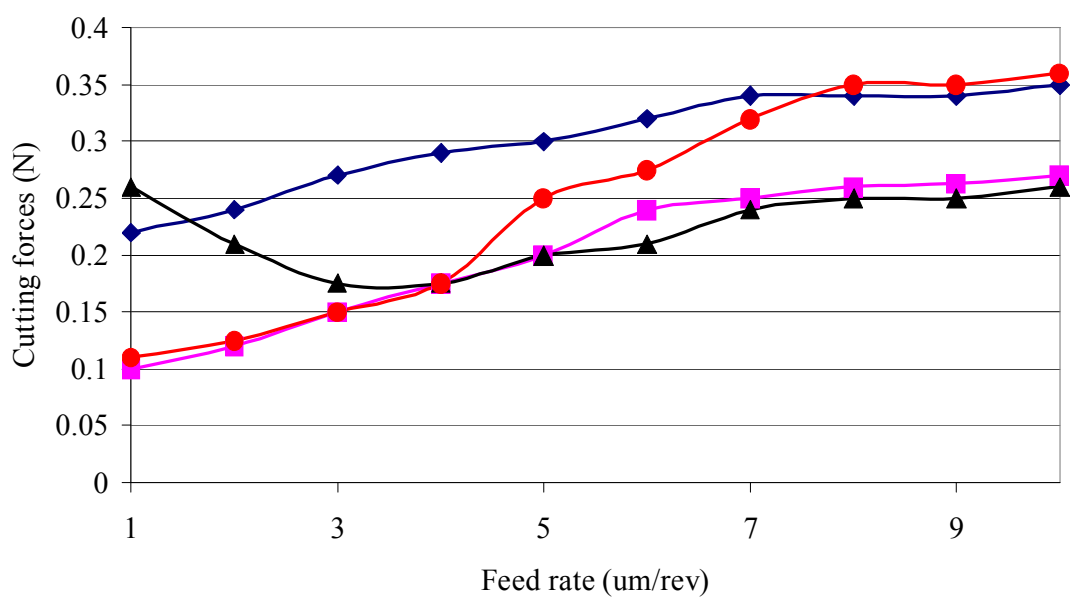

Fn (sample 1) - - Ft (sample 1) $₫$ - Fn (sample 2) - - Ft (Sample 2)

Fig. 6 Variation of cutting forces against feed rate 
process. Fig. 6 shows the cutting forces for cutting sample 1 and sample 2 under different feed rates. It can be seen that the cutting forces were all at sub-Newton level. The negative rake angle tool contributed to increased compressive stress in front of the tool. Such stress state is favourable to "suppress" fracture damage. Therefore, it was found that the normal cutting forces are bigger than the tangential cutting forces under feed rates from $1 \mu \mathrm{m} / \mathrm{rev}$ to $10 \mu \mathrm{m} / \mathrm{rev}$. However, as shown in Fig. 6 when cutting sample 2 the normal cutting force became smaller than the tangential cutting force. It indicated that the ductile mode cutting condition had changed to brittle mode. After cutting sample 2 the diamond tool was then inspected.

Tool wear. The diamond tool was inspected by a SEM before and after the cutting trials. The SEM

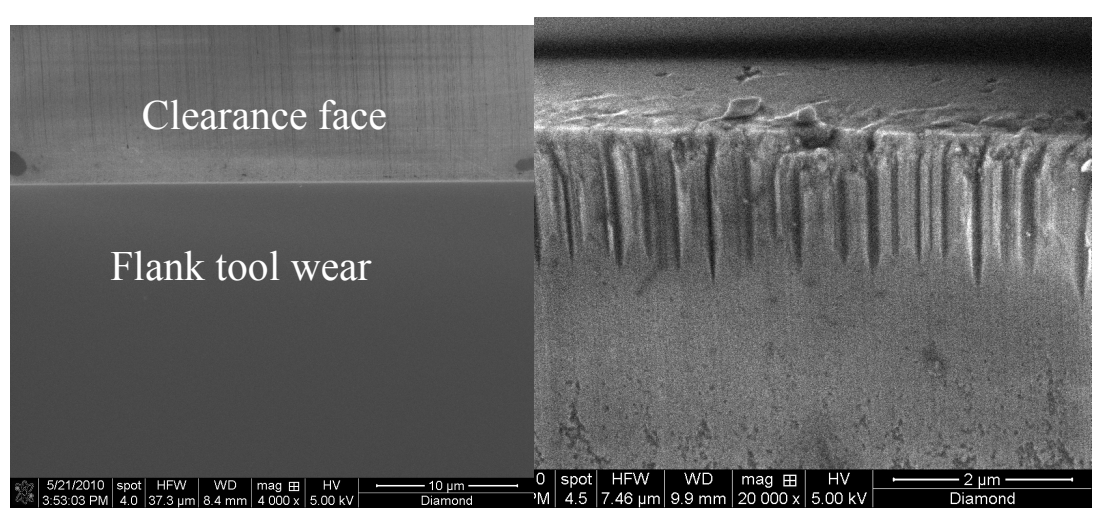

(a) Before cutting trials (b) After cutting trial (cutting distance of $8 \mathrm{~km}$ )

Fig. 7 SEM images of the cutting edge of the diamond tool before and after the cutting trials images are shown in Fig. 7. Clear tool flank wear was observed after a cutting distance of $8 \mathrm{~km}$ on the cutting edge which was in the form of many microgrooves. This is a strong indication of the development of abrasive wear in its early stage. The width of flank tool wear (VB) measured by SEM was only $1.36 \mu \mathrm{m}$. The tool wear changed the original brittle-ductile transition condition and caused brittle fractures on the machine surface. Therefore, the surface roughness of machined surface on sample 2 was higher than that on sample 1.

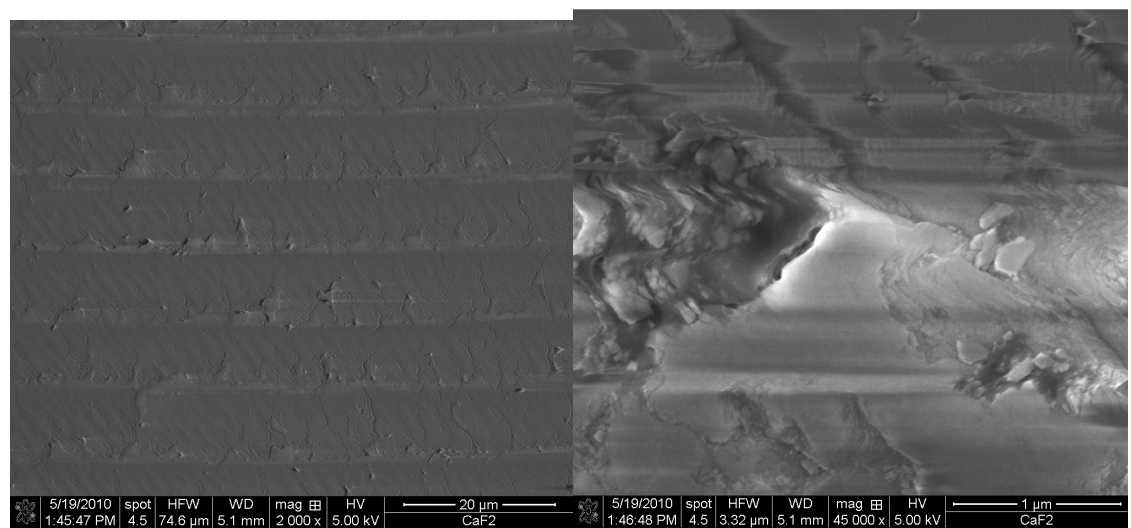

(a) Overall view of brittle fractures (b) Zoomed brittle fractures

Fig. 8 Brittle fracture on the machined surface (sample 2)

Fig. 8 shows machined surface topography measured by SEM and a zoomed image. The size of fractures is within 1 to $2 \mu \mathrm{m}$. This is the so-called A-type brittle fracture. B-type brittle fractures were not observed on the machined surface. This showed that using white spirit can improve thermal conditions. But further cutting trials are needed in the future to

confirm the tool life when using a feed rate less than $5 \mu \mathrm{m} / \mathrm{rev}$.

Another $\mathrm{CaF}_{2}$ work piece (Sample 3) was cut by using a feed rate of $10 \mu \mathrm{m} / \mathrm{rev}$, a depth of cut of 10 $\mu \mathrm{m}$ and white spirit as the coolant. After a cutting distance of $6 \mathrm{~km}$ brittle fractures appeared on the machined surface. The size of brittle fracture was also of the order of 1 to $2 \mu \mathrm{m}$. This further confirmed that white spirit helps to reduce thermal brittle fracture. 


\section{Conclusions}

Through the experimental studies, the following conclusions can be drawn:

(1) Nanosmooth diamond turned $\mathrm{CaF}_{2}$ optical surfaces were obtained when a feed rate from $1 \mu \mathrm{m} / \mathrm{rev}$ to $10 \mu \mathrm{m} / \mathrm{rev}$, depth of cut of $10 \mu \mathrm{m}$, spindle speed of $1200 \mathrm{rpm}, \mathrm{a}-15^{\circ}$ rake angle diamond tool and white spirit as the coolant were used.

(2) Surface roughness (Ra) of $2 \mathrm{~nm}$ and form accuracy (PV) of $26 \mathrm{~nm}$ on the machined surface of $\mathrm{CaF}_{2}$ optics were obtained when using a feed rate of $1 \mu \mathrm{m} / \mathrm{rev}$.

(3) A feed rate of less than $5 \mu \mathrm{m} / \mathrm{rev}$ is recommended for better form accuracy and high machining efficiency.

(4) White spirit is a suitable coolant for cutting $\mathrm{CaF}_{2}$ optics as B-type brittle fracture, which is related to thermal effects, did not occur in the experiment.

\section{Acknowledgement}

The authors would like to thank EDTC, Mr. Mat Norris from Spanoptic, Mr. Andrew Cox from Contour Fine Tooling, Prof. Paul Shore, Dr. Paul Comley and Mr. Alan Heume for providing financial support, $\mathrm{CaF}_{2}$ specimens and access to the Moore Nanotech 350 UPL for diamond turning trials in this project.

\section{References}

[1] D.J. Ewing, Excimer lasers at 30 years, Opt. Photonics News 14 (2003) 26-31.

[2] D.L. Decker, D.J. Grandjean, J.M. Bennett, Optical and surface physical characteristics of diamond-machined infrared windows, NBS Spec. 562 (1979) 293-304.

[3] J. Yan, K. Syoji, J. Tamaki, Crystallographic effect in micro/nanomachining of single-crystal calcium fluoride, J. Vac. Sci. Technol. B22 (2004) 46-51.

[4] E.R. Marsh, B.P. John, J.A. Couey, J. Wang, R.D. Grejda, R.R. Vallance, Predicting surface figure in diamond turned calcium fluoride using in-process force measurement, J. Vac. Sci. Technol. B23 (2005) 84-89.

[5] Y. Nambaa, N. Ohnishia, S. Yoshidaa, K. Harada, Y. Yoshida, T. Matsuo, Ultra-precision float polishing of calcium fluoride single crystals for deep ultra violet applications, CIRP Ann.-Manufacturing Technology 53 (2004) 459-462.

[6] J. Yan, J. Tamaki, K. Syoji, T. Kuriyagawa, Single point diamond turning of $\mathrm{CaF}_{2}$ for nanometric surface, Int. J. Adv Manuf Tech. 24 (2004) 640-646.

[7] P. Blake, R.O. Scattergood, Ductile-regime machining of germanium and silicon, J, Am. Ceram. Soc. 73 (1990) 949-957. 
Proceedings of Precision Engineering and Nanotechnology 10.4028/www.scientific.net/KEM.516

Single Point Diamond Turning of Calcium Fluoride Optics 10.4028/www.scientific.net/KEM.516.408 